C/ORNL95-0375

CRADA Final Report

for

CRADA number ORNL95-0375

\title{
IMPROVED MATERIALS FOR USE AS COMPONENTS IN KRAFT BLACK LIQUOR RECOVERY BOILERS
}

\author{
J. R. Keiser \\ G. A. Aramayo \\ G. M. Goodwin \\ P. J. Maziasz \\ Oak Ridge National Laboratory \\ J. P. Gorog \\ Weyerhaeuser Company
}

\author{
Prepared by the \\ Oak Ridge National Laboratory \\ Oak Ridge, Tennessee 37831 \\ managed by \\ Lockheed Martin Energy Research \\ Corporation \\ for the \\ U.S. Department of Energy \\ under contract DE-AC05-96OR22464
}




\title{
APPROVED FOR PUBLIC RELEASE
}

C/ORNL95-0375

\author{
CRADA Final Report \\ for \\ CRADA Number ORNL95-0375
}

\section{IMPROVED MATERIALS FOR USE AS COMPONENTS IN KRAFT BLACK LIQUOR RECOVERY BOILERS}

\author{
J. R. Keiser \\ G. A. Aramayo \\ G. M. Goodwin \\ P. J. Maziasz \\ Oak Ridge National Laboratory \\ J. P. Gorog \\ Weyerhaeuser Company
}

\author{
Prepared by the \\ Oak Ridge National Laboratory \\ Oak Ridge, Tennessee 37831 \\ managed by \\ Lockheed Martin Energy Research Corporation \\ for the \\ U. S. department of Energy \\ under contract DE-AC05-96OR22464
}




\section{CONTENTS}

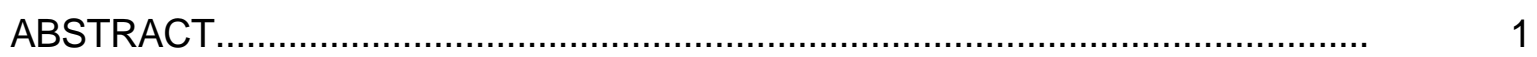

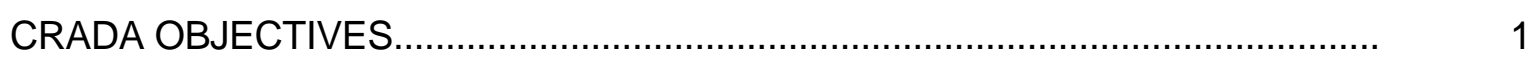

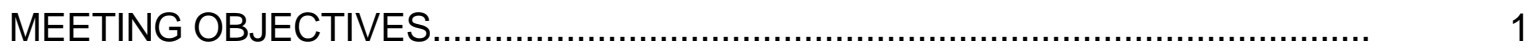

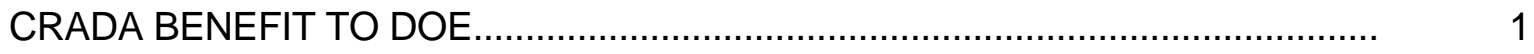

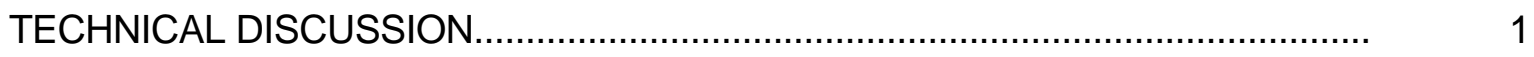

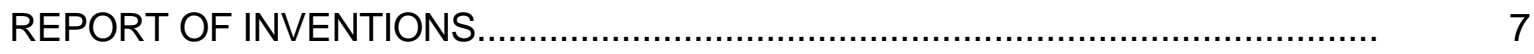

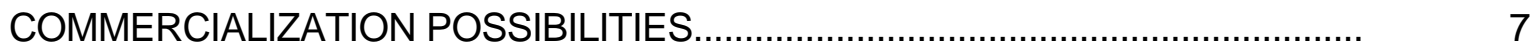

PLANS FOR FUTURE COLLABORATION......................................................... 8

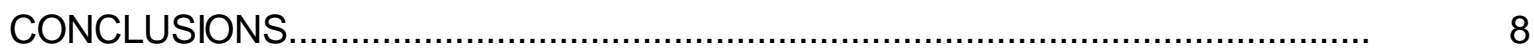

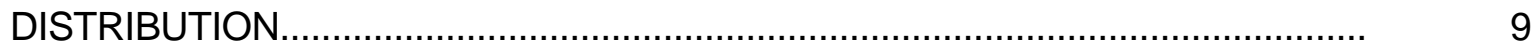

Research sponsored by the U. S. Department of Energy, Assistant Secretary for Energy Efficiency and Renewable Energy, Office of Industrial Technologies, Advanced Industrial Materials Program, under contract DE-AC05-96OR22464 with Lockheed Martin Energy Research Corporation. 


\begin{abstract}
This Cooperative Research and Development Agreement (CRADA) was undertaken to evaluate current and improved materials and materials processing conditions for use as components in kraft black liquor recovery boilers and other unit processes. The main areas addressed were: 1) Improved Black Liquor Nozzles, 2) Weld Overlay of Composite Floor Tubes, and 3) Materials for Lime Kilns. Iron aluminide was evaluated as an alternate material for the nozzles used to inject an aqueous solution known as black liquor into recovery boilers as well for the uncooled lining in the ports used for the nozzles. Although iron aluminide is known to have much better sulfidation resistance in gases than low alloy and stainless steels, it did not perform adequately in the environment where it came into contact with molten carbonate, sulfide and sulfate salts. Weld overlaying carbon steel tubes with a layer of stainless weld metal was a proposed method of extending the life of recovery boiler floor tubes that have experienced considerable fireside corrosion. After exposure under service conditions, sections of weld overlaid floor tubes were removed from a boiler floor and examined metallographically. Examination results indicated satisfactory performance of the tubes. Refractory-lined lime kilns are a critical component of the recovery process in kraft pulp mills, and the integrity of the lining is essential to the successful operation of the kiln. A modeling study was performed to determine the cause of, and possible solutions for, the repeated loss of the refractory lining from the cooled end of a particular kiln. The evaluation showed that the temperature, the brick shape and the coefficient of friction between the bricks were the most important parameters influencing the behavior of the refractory lining.
\end{abstract}

\title{
CRADA Objectives
}

The desired result of this CRADA was to provide an evaluation of certain materials in selected paper mill environments. The specific objectives of this CRADA were:

-Determine the suitability of iron aluminide for liquor nozzle applications,

-Evaluate use of stainless steel weld overlay on recovery boiler carbon steel floor tubes

-Identify the cause of and solution for refractory lining loss in lime kilns.

\section{Meeting Objectives}

Objectives were met by timely joint cooperative work between Weyerhaeuser and ORNL staff.

\section{CRADA Benefit to DOE}

The research conducted under this agreement served to increase the knowledge and understanding of the performance of the selected materials in the specific environments. Identification of more suitable materials or processes resulted in operation that was more energy efficient and safe.

\section{Technical Discussion}

\section{Introduction}

The purpose of this Cooperative Research and Development Agreement (CRADA) was to determine the suitability of certain materials for some specific applications in black liquor recovery boilers and in lime kilns of kraft paper mills. 
The main functions of kraft black liquor recovery boilers are to recover process chemicals used for production of paper and to supply steam for use in paper making processes and for producing electrical power. Black liquor nozzles are part of the injection system for these boilers. Due to conditions in boilers, the nozzles of the black liquor injection system are replaced in as little as two to four weeks. Under some circumstances, nozzle failure can result in conditions which may cause explosions. In addition, some failure modes result in detrimental effects on the black liquor spray distribution which then affects the efficiency or causes plugging of the boiler. The objectives of this effort were to determine why there is such a large variability in performance of nozzles, to understand the mechanism leading to failure, and to identify and evaluate improved materials or designs which would lead to nozzles which operate at least one year.

Over the last four years, thinning of the 304L stainless steel (SS) clad layer has been observed adjacent to the point where the extensions of the front wall tubes are butt-welded to the carbon steel floor tubes. Consequences of the thinning include safety concerns related to potential smelt-water explosions and increased down time for repair. To avoid complete tube replacement, a currently recommended repair is to build up the thickness of the cladding by use of a stainless steel weld overlay. One objective of this CRADA was to gain an understanding of the weld overlay process and of the characteristics of the weld overlay coatings, and to evaluate the performance of such repaired components in order to optimize the materials and processes. The effort in this area focused on residual stress measurements and modeling of pre-and postexposed weld overlay composite tubes.

The lime kiln is a critical part of the recovery process. Calcium oxide or lime is produced by removing carbon dioxide from calcium carbonate. This process is accomplished by exposing the calcium carbonate to intense heat in a long, slightly-sloped, rotating, cylindrically-shaped, refractory-lined lime kiln. The slight tilt and rotation of the vessel cause material to move from the higher to the lower end of the vessel. The refractory lining is needed in order to maintain a sufficiently high temperature in the kiln as well as to protect its steel shell. On several recent occasions, the refractory bricks at the lower end of a kiln have fallen out, causing a serious disruption in operation. The objective of this task was to perform finite element analyses of the thermal and mechanical responses of refractory bricks in order to identify the cause of the loss of stability of the brick structure as well as to identify possible remedies.

\section{Black Liquor Nozzle Studies (J. R. Keiser, G. M. Goodwin and P. J. Maziasz)}

Figure 1a shows a new black liquor splash-plate-type nozzle while Fig. $1 b$ shows a degraded one which has lost the majority of the barrel and a portion of the splash plate surface due to corrosion and/or erosion. For this study, splash-plate-type nozzles were prepared with new parts and with parts that had seen some service, i.e. a repair approach. In both cases, approximately $4.8 \mathrm{~mm} \mathrm{(3/16} \mathrm{in.)} \mathrm{of} \mathrm{the} \mathrm{top} \mathrm{surface} \mathrm{of} \mathrm{the} \mathrm{splash} \mathrm{plate} \mathrm{was} \mathrm{machined} \mathrm{away} \mathrm{and}$ replaced by two layers of gas tungsten arc (GTA) iron aluminide weld metal, each about $3.2 \mathrm{~mm}$ (1/8 in.) thick. The top surface was then machined bringing the part back to its original thickness. The leading edge of the nozzle barrel was also overlaid with a single layer of iron aluminide weld metal. A second type of nozzle, a swirl-cone type, was overlaid with iron aluminide using both new and post-service parts. The leading edges of the cones were removed and replaced with GTA weld metal as were the outlet orifices. The parts were then machined back to the original dimensions. Both types of liquor nozzles, like those shown in Fig. 2 , were installed in mills in North America.

Liquor nozzle ports are formed using six plates arranged in a hexagonal array (two long plates 

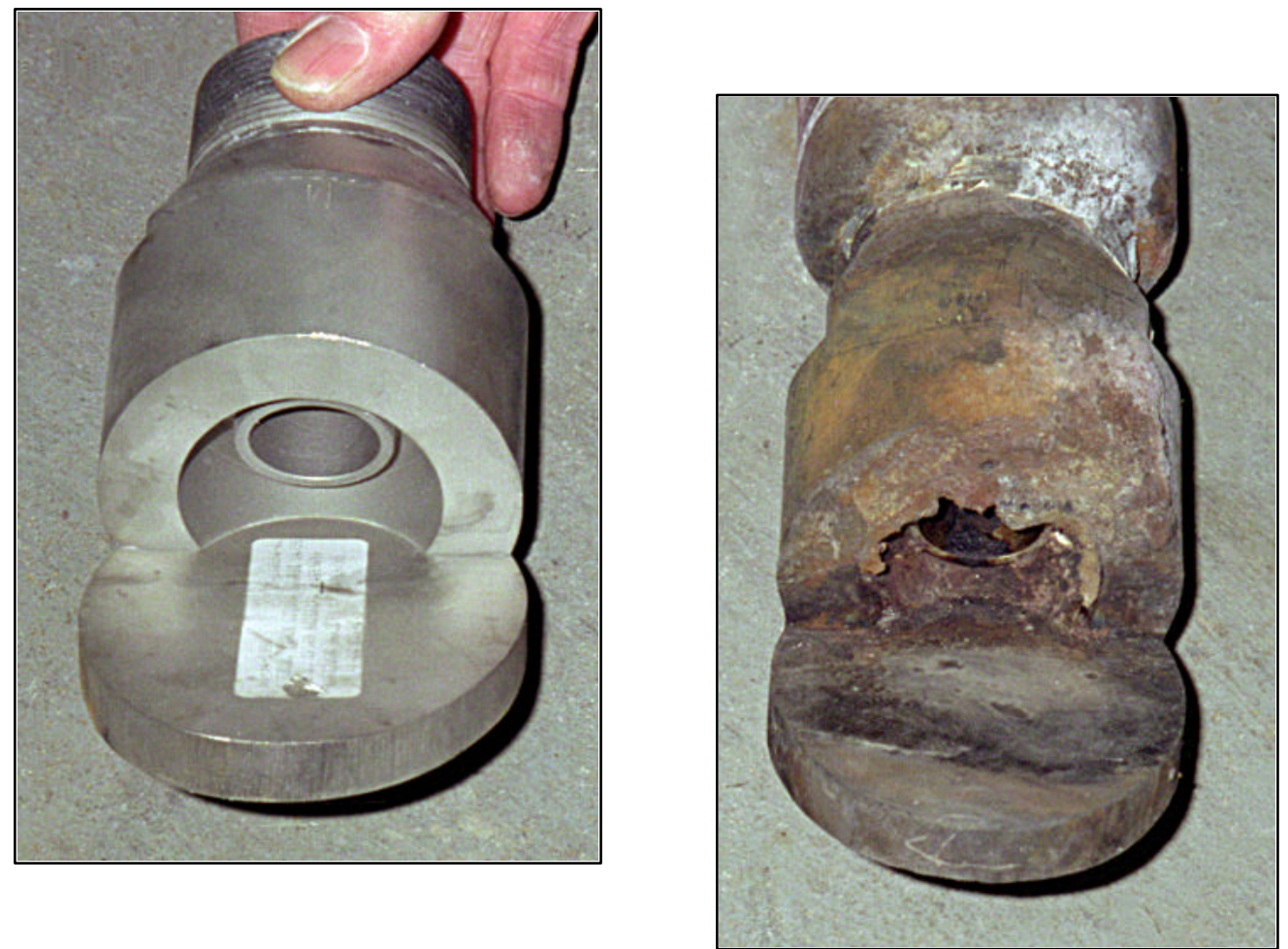

on the sides, short plates on tops and bottoms) to form a box to protect the water wall tubes. Four sections of a liquor gun port lining were fabricated from $6.4 \mathrm{~mm}(1 / 4 \mathrm{in}$.) thick stainless

Fig. 1 Splash plate type liquor nozzles a) unexposed and b) degraded.
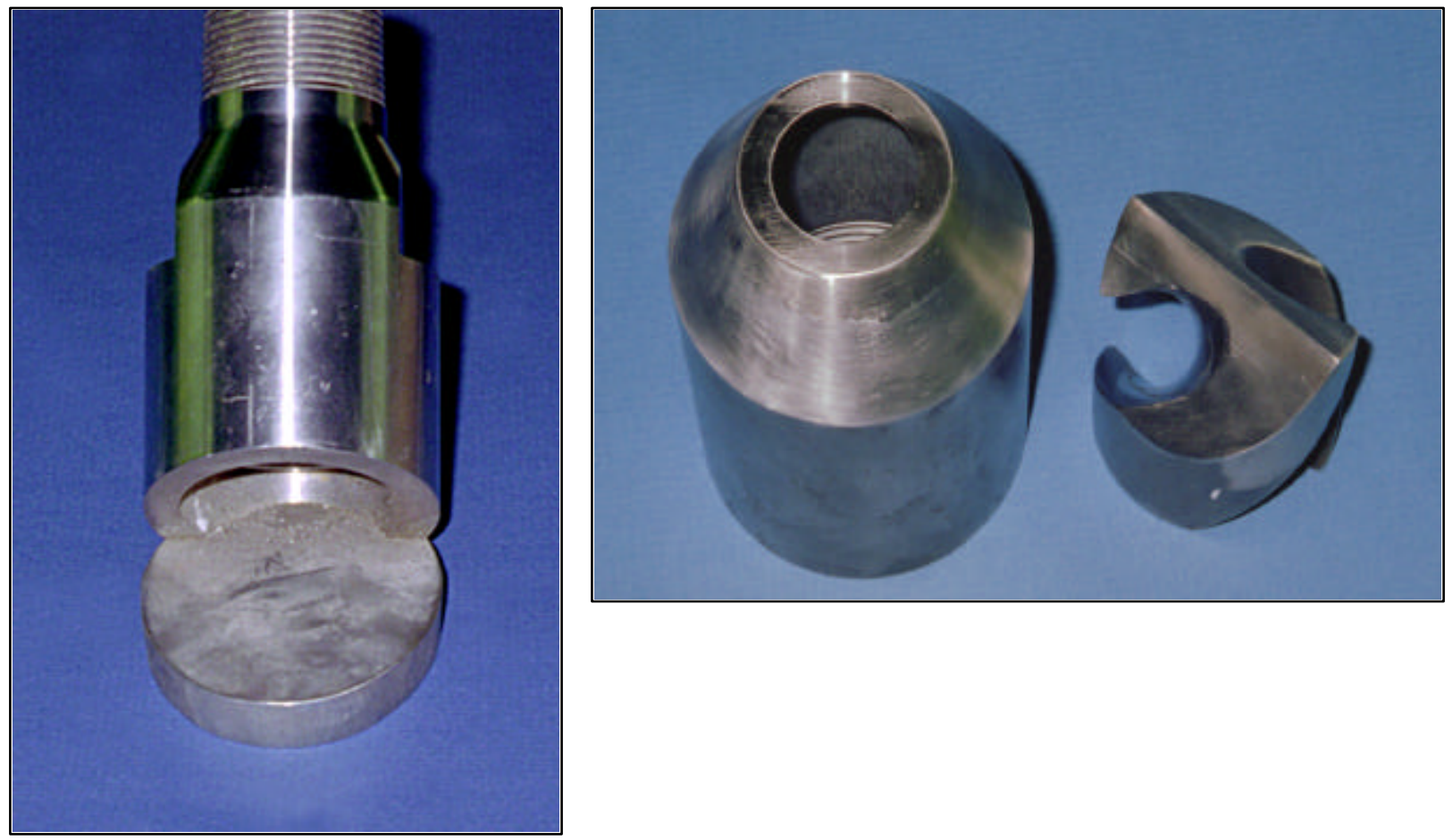
Fig. 2 Splash plate and swirl type liquor nozzles after application of iron aluminide. steel plate and then overlaid with a pad of iron aluminide weld metal. The plates were installed in a mill in the south central U.S. and their performance monitored by periodic visual examinations by mill personnel.

Experience with the iron aluminide liquor nozzles and liquor port linings showed that the iron aluminide did not provide good corrosion resistance. Apparently, molten salts drip on and splash on the nozzles and linings, and these salts are so aggressive that the aluminide is corroded at an unacceptably high rate. Consequently, it was concluded that the corrosion resistance of iron aluminide was not sufficient to give satisfactory service under the molten salt conditions experienced by liquor nozzles and port linings of a black liquor recovery boiler.

\section{Composite Tube Weld Overlay Repairs (J. R. Keiser and G. M. Goodwin)}

The pressurized water in the wall and floor tubes of a recovery boiler subjects the tubes to pressures that are generally in the range of 41 to $102 \mathrm{~atm}$ (600-1500 psi) depending on the boiler design. Consequently, it is essential that the wall thickness of the tubes remains greater than the minimum prescribed by the boiler and pressure vessel code. On slope-floored boilers, experience has shown that some thinning occurs, particularly at the higher end of the floor where the stainless steel/carbon steel co-extruded wall tubes are bent at an $80+\mathrm{E}$ angle and then butt welded to the carbon steel floor tubes. The thinning occurs on the carbon steel tubes just below the butt welds. One repair method being considered as a means to provide protection to the thinning tubes is application of a weld overlay of stainless steel.

The Weyerhaeuser mill in Columbus, MS is one where this floor tube thinning was observed. Consequently, arrangements were made to have a weld overlay applied to a short length of the floor tubes near the front wall during the April, 1995 shutdown. The lower boiler during application of the weld overlay is shown in Fig. 3. During subsequent shutdowns, visual inspections of the overlaid floor tubes were made, and, after a year's exposure, a few short sections were removed for metallographic examination. Figure 4 shows a section of the weld overlaid floor tubes after a year's exposure. Residual stress measurements were not made in tube sections that were removed because removal of the sections from the floor relieved most of the stresses that were developed during the overlay process. However, the deformation of the weld-overlaid floor tubes suggested that significant stresses were developed in the tubes as a result of the application of the weld overlay.

Cross sections were taken from the weld overlaid tubes that had been removed from the floor, and these sections were examined metallographically. Results of the examination showed that field application of the weld metal resulted in less than ideal quality. The weld surface showed some significant irregularities, and some porosity was evident. An example is shown in Fig. 5. As shown in Fig. 6, the depth of the heat affected zone varied appreciably along the surface which is not unexpected given the difficulties associated with the field application. Despite these shortcomings, the overall appearance and condition suggest that the weld overlay provided the desired protection of the carbon steel tubes.

\section{Lime Kiln Refractory Studies (G. A. Aramayo and J. R. Keiser)}

The refractory lining of a lime kiln at the Weyerhaeuser mill in Grande Prairie, Alberta, experienced repeated failures over a few months time. In this case, failure consisted of a loosening and eventual falling out of the bricks in the first ten rows of refractory in the lower or 
discharge end of the kiln. In order to determine the root cause of the refractory brick loss, a

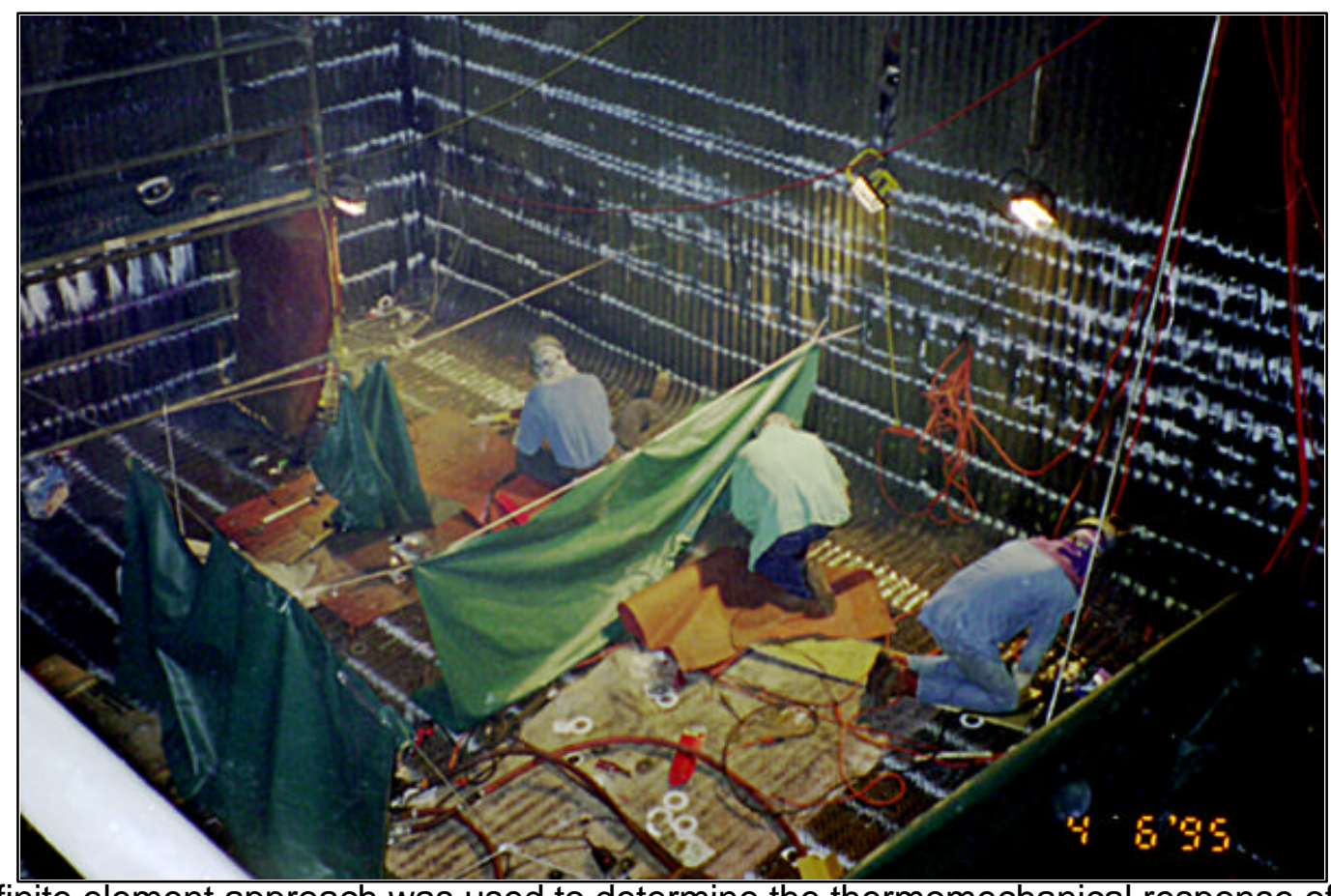

finite element approach was used to determine the thermomechanical response of a single ring

Fig. 3 Weld overlay being applied to floor tubes of Columbus, MS, recovery boiler.

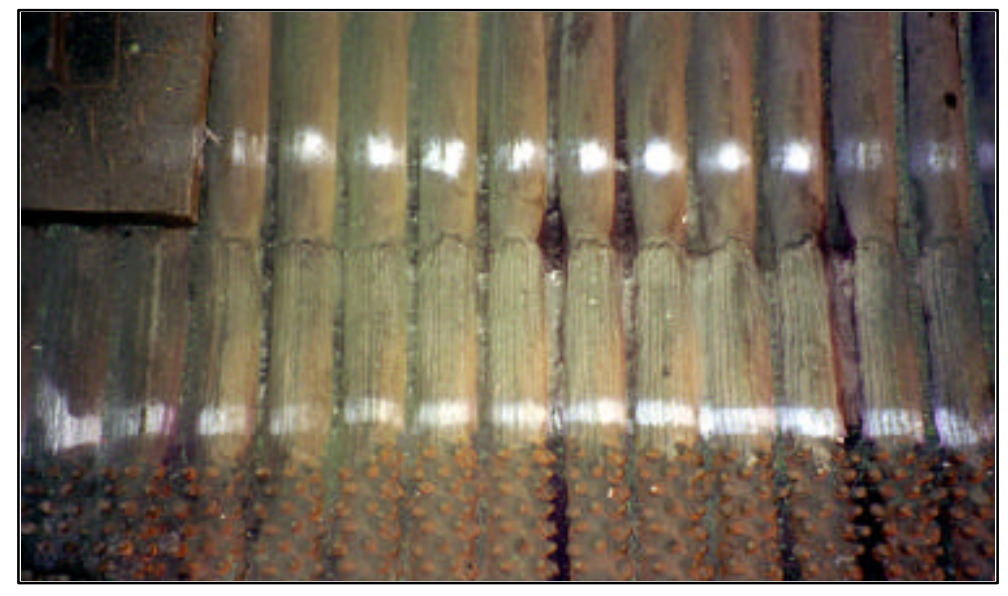




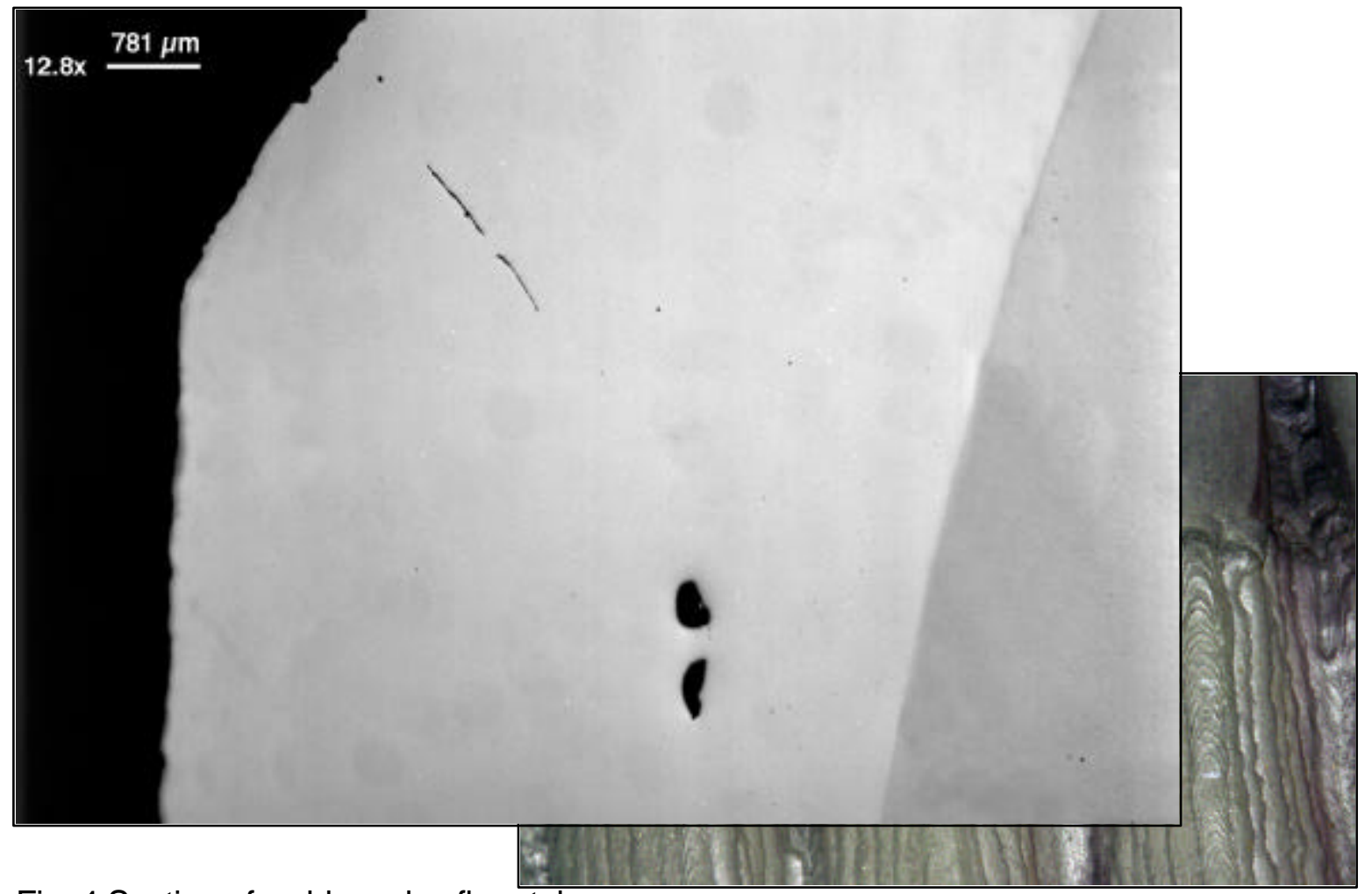

Fig. 4 Section of weld overlay floor tube.

Fig. 5 Cross section of weld overlaid tube showing lack of fusion and porosity.

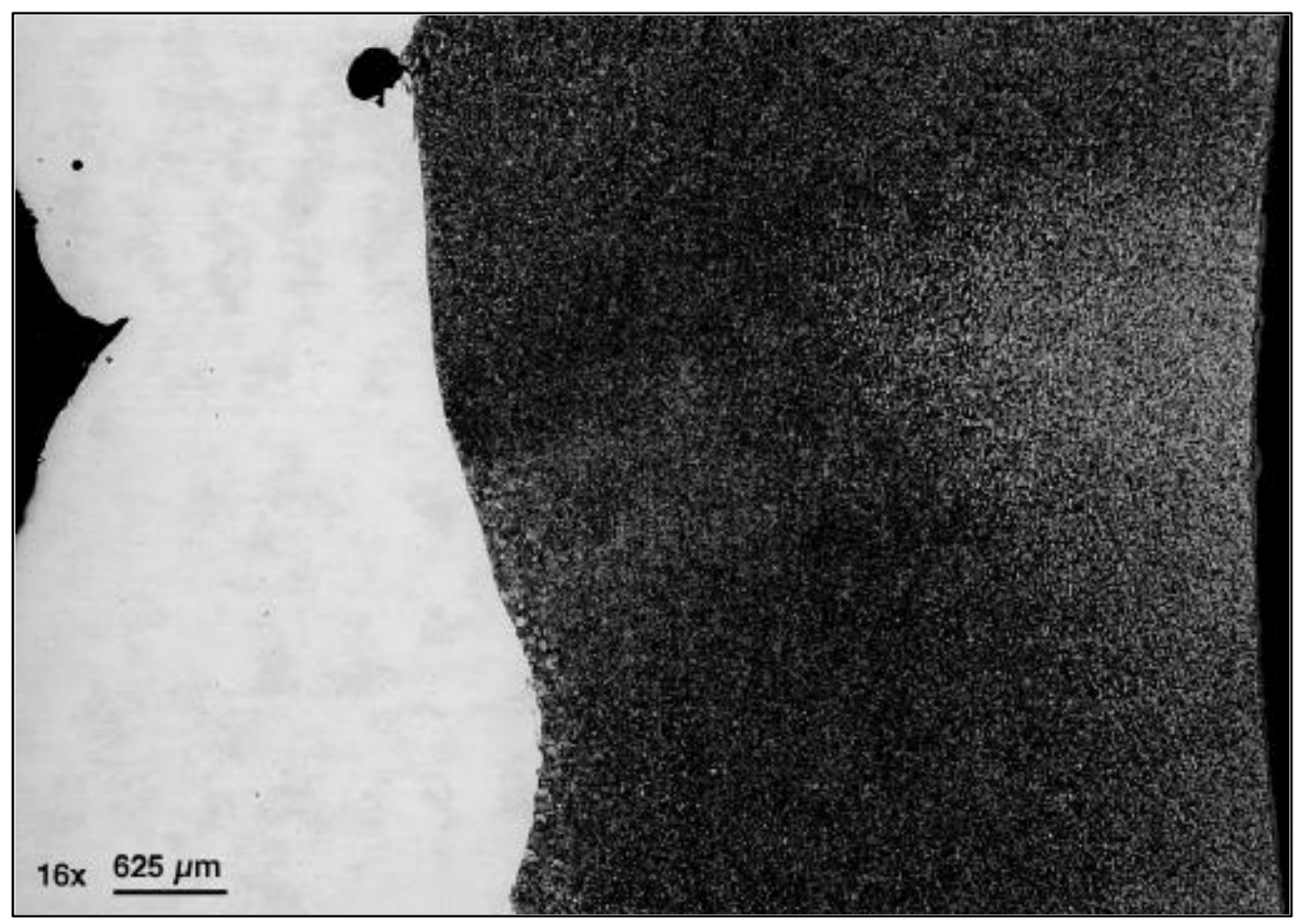


Fig. 6 Etched cross section of weld overlaid tube where darkened areas indicate heat affected zone.

of refractory brick, insulation, and the structural steel shell. Figure 7 shows the finite element used to describe the lime kiln/cooler configuration. The shell response was determined for two different temperature profiles across the wall of the kiln at the failure location. In addition, the effects of mortar at the brick interfaces and between the brick and insulation were investigated. Lastly, the effects on the lining stability associated with the choice of brick size was studied.

The finite element analysis showed that an increase in the shell deformation decreases system structural stability but must be due to something other than thermal effects. With regard to the interaction between the lime kiln's internal components, an increase in the friction at the brickto-brick and brick-to-insulation interfaces increases the stability of the system, as does an incremental increase in the bonding strength of the mortar at the brick-to-insulation interface.

Temperature changes can have an important effect. An increase in temperature of the brick results in an increase in stability of the system if the increase in temperature of the shell is comnarable in maanitude. However an increase in temnerature of the shell laraer than that of

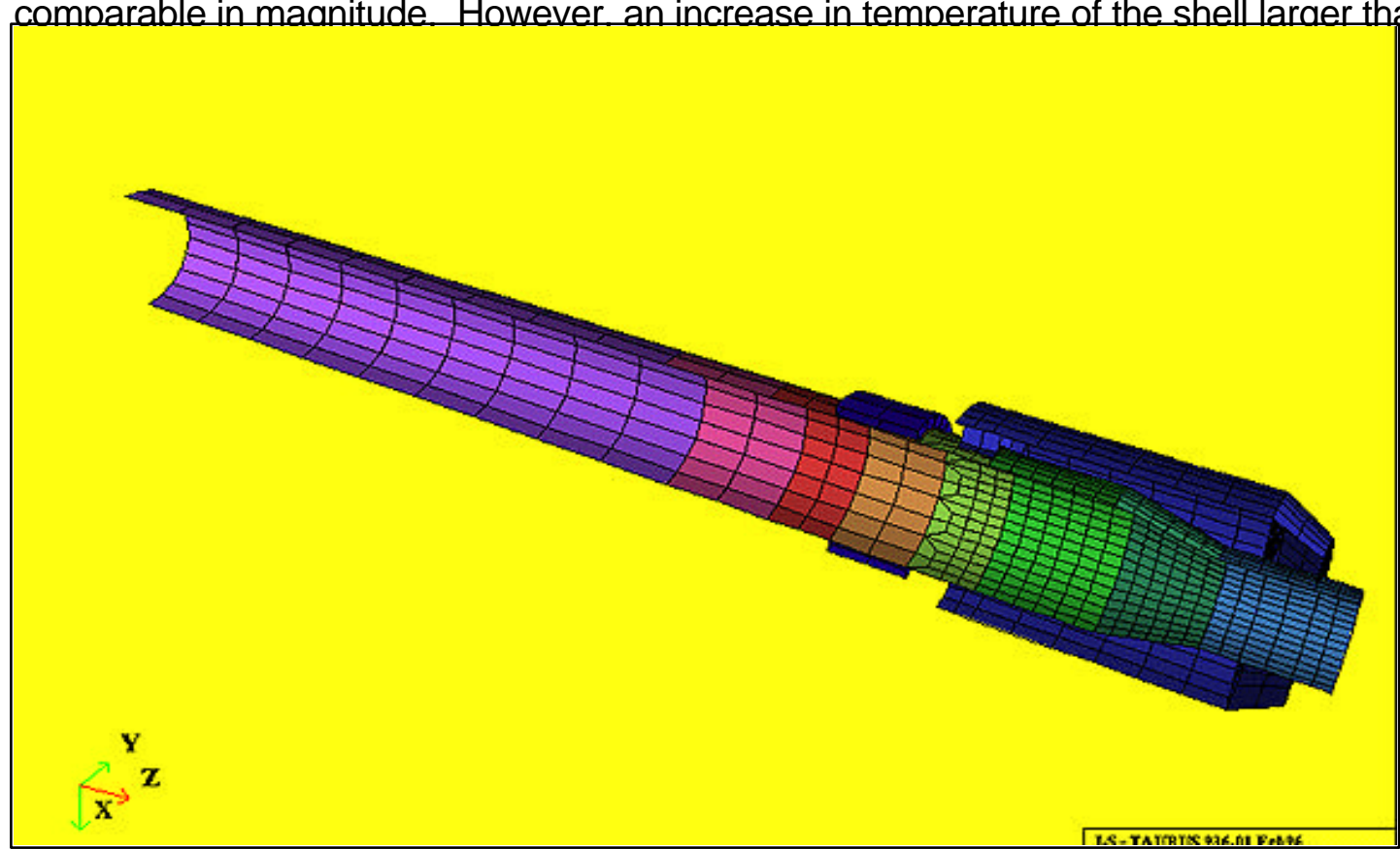

Fig. 7 Finite element model of the lime kiln/cooler configuration.

The geometry of the bricks was also shown to have an effect. Bricks with a larger aspect ratio (brick chord length to brick depth) form a more stable structure than bricks with a lower one. It appears that a combination of bricks with different tapers tend to have lower structural stability than bricks with appropriate aspect ratios and a common degree of taper.

This analysis established that issues like brick-to-brick and brick-to-insulation interactions, the temperature changes of the system and the geometry of the bricks all have a role in the stability of the refractory liner. However, the quality of the installation was determined to have an 
overriding role in that a poor installation would result in an unacceptable performance of a very well designed system.

\section{$\underline{\text { Conclusions }}$}

For black liquor nozzles and liquor port liners, iron aluminides did not show an improvement in resistance to molten smelt. Consequently, aluminides were not deemed to be significantly better than the materials currently in use. The stainless steel weld overlay applied to the recovery boiler floor tubes apparently provided resistance to thinning but resulted in the development of appreciable stresses in the tubes. Consequently, it was decided that in-situ weld overlay would not be used to provide protection for carbon steel floor tubes. Finite element modeling of the lime kiln bricks, insulation and shell showed the effects of temperature changes, brick geometry and component interaction on the stability of the refractory brick lining.

Subsequently, it was determined that the quality of refractory installation played a critical role in determining the stability of any refractory brick arrangement.

\section{Report of Inventions}

There were no inventions developed under this agreement.

\section{Commercialization Possibilities}

The information obtained as a result of the work done for this CRADA is of benefit to Weyerhaeuser in selecting materials for application in selected areas of their paper mills.

\section{Plans for Future Collaborations}

A new CRADA calling for work on topics addressing other recovery boiler problems as well as materials issues in black liquor gasification is planned.

\section{Conclusions}

The technical objectives of this CRADA were met in a timely manner through the close cooperation of personnel at the Weyerhaeuser facilities and ORNL. It was determined that iron aluminide does not provide improved resistance to the environment encountered by liquor nozzles, a stainless steel weld overlay on floor tubes does provide improved corrosion resistance but results in distortion of the tubes, and the stability of lime kiln refractories is strongly influenced by the temperature, brick shape and coefficient of friction for lining system components. 


\section{DISTRIBUTION}

1. C. A. Sorrell, Office of Industrial Technologies, DOE-HQ, EE-23, 1000 Independence Avenue, S.W., Washington, DC 20585

2-3. Office of Scientific and Technical Information, P. O. Box 62, Oak Ridge, TN 37831

4. Work for Others Office, DOE-ORO, G-209, P. O. Box 2001, Oak Ridge, TN 37831

5. P. L. Gorman, DOE-ORO, Site Office, P. O. Box 2008, Oak Ridge, TN 37831-6269

6. J. P. Gorog, WTC 2H22, Weyerhaeuser Company, Tacoma, WA 98477-0001

7. M. H. Rawlins, DOE-ORO, Site Office, P. O. Box 2008, Oak Ridge, TN 37831-6269

8. P. Angelini

9. G. A. Aramayo

10. E. E. Bloom

11. R. A. Bradley

12. R. G. Gilliland

13-14. D. R. Hamrin

15-16. J. R. Keiser

17. A. J. Luffman

18. P. J. Maziasz

19. A. E. Pasto

20. A. C. Schaffhauser

21. P. F. Tortorelli

22. C. A. Valentine 